\title{
Assessment of Inorganic Pollutant Contamination in Groundwater using Ground Penetrating Radar (GPR)
}

\author{
Y.N.S. Wijewardana, L.W. Galagedara ${ }^{1}$, M.I.M. Mowjood ${ }^{1 *}$ and K. Kawamoto ${ }^{2}$ \\ Postgraduate Institute of Agriculture \\ University of Peradeniya \\ Sri Lanka
}

\begin{abstract}
The objective of this study was to evaluate the ground penetrating radar $(G P R)$ wave responses to different levels of electrical conductivity (EC) in contaminant plumes. GPR wave simulations were carried out using GprMax2D and the simulated data were compared with GPR surveys on Lysimeter test. Trace amplitude of the reflected wave was plotted with two-way travel time and the $2 D$ GPR images were developed to observe the variation of GPR responses with increasing EC. Simulation study showed the disappearance of the subsurface reflection and wave amplitude reaching zero at higher EC levels (when $E C>0.28 \mathrm{~S} / \mathrm{m}$ ). In addition, when the EC level was higher, the plume thickness did not have a significant effect on the amplitude of the reflected wave. However, it was also found that reflected signal strength decreases with increasing plume thickness at a given EC level. Further research is needed to verify the results under heterogeneous aquifer conditions.
\end{abstract}

Keywords: Ground penetrating radar, groundwater, landfill leachate, solid waste dump site

\section{INTRODUCTION}

Municipal solid waste (MSW) in open dump sites produces liquid product called "leachate" which contains various hazardous contaminants such as organic contaminants and heavy metal (Robert and David, 1997) adversely affecting ground and surface water quality (Kelly, 1976). Therefore, there is an urgent need to assess groundwater contamination due to improper MSW dumping sites. Non-destructive geophysical methods have been tested by several researchers studying contaminant plumes originating from landfill leachate (Calabrese et al., 2004; Roy et al., 2009). Hermozilha et al. (2010) employed ground penetrating radar (GPR) and resistivity surveys to evaluate landfill contamination plumes. Understanding of real field situation can be supported with modelling, where Lee and Wang (2009) showed that GPR wave simulation using GprMax2D can detect the difference of the relative permittivity of adjacent layers. The GPR method works by transmitting pulses of ultra - high frequency radio waves (generally in the range of $10-1200 \mathrm{MHz}$ ) down into the ground through an antenna. These waves propagate depending on the electrical properties of subsurface materials and subjected to scattering, reflection, deflection and refraction (Davis and Annan, 1989). Objective of this study was to evaluate the GPR wave responses to different electrical conductivity (EC) levels in contaminant plumes using a lysimeter and GPR wave simulation using GprMax2D software.

Department of Agricultural Engineering, Faculty of Agriculture, University of Peradeniya, Sri Lanka.

2 Graduate School of Science and Engineering, Saitama University, 255 Shimo-okubo, Sakura-ku, Saitama, 3388570, Japan

Corresponding Author: mowjood2010@gmail.com 


\section{METHODOLOGY}

\section{GPR wave simulation using GprMax2D for contaminated and control zone}

A conceptual model was developed with four layers, each having a different relative permittivity, $\varepsilon_{r}$, as shown in Figure 1. The 2D model domain was $4.0 \mathrm{~m} \times 3.0 \mathrm{~m}$ and targeted penetration depth was $1.5 \mathrm{~m}$. Iron bars were used as underground reflectors where amplitude variation of reflected waves would be studied under different contaminant levels. Coordinates (x, y, r) of the A and B iron bars were 1.0, 1.2254, 0.0254 and 3.0, 1.2254, 0.0254 , respectively where $\mathrm{r}$ is the radius of the bar (Figure 1). A leachate plume was introduced to the saturated sand between $2.0 \mathrm{~m}$ and $3.0 \mathrm{~m}$ along the $\mathrm{x}$-axis (Figure 1). Three different model series were run under three different conditions by introducing different EC levels and plume thicknesses (Table 1).

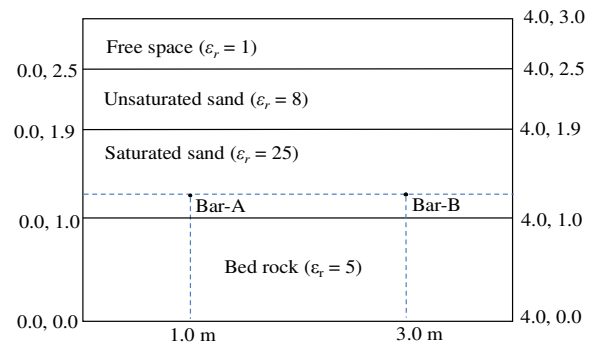

Fig. 1. Schematic diagram of the conceptual four layer model

Table 1. Modeling series with GprMax 2D, the model conditions, level of EC in each plumes and plume thicknesses

\begin{tabular}{|c|c|c|c|}
\hline $\begin{array}{l}\text { Model } \\
\text { series }\end{array}$ & Conditions & $\begin{array}{l}\text { EC } \\
(\mathrm{S} / \mathrm{m})\end{array}$ & $\begin{array}{l}\text { Coordinates of plume } \\
(x \text { and } y \text { in } m)\end{array}$ \\
\hline Series I & No plume & 0.0 & No plumes \\
\hline Series II & $\begin{array}{l}\text { Different EC } \\
\text { values for } \\
3 \text { plume thickness }\end{array}$ & $\begin{array}{l}0.01 \text { to } 0.35 \text { at } \\
0.01 \text { increment }\end{array}$ & $\begin{array}{l}\text { Plume } 1(2,1.7 ; 3,1.9) \\
\text { Plume } 2(2,1.5 ; 3,1.9) \\
\text { Plume } 3(2,1.1 ; 3,1.9)\end{array}$ \\
\hline Series III & $\begin{array}{l}\text { Different plume } \\
\text { thicknesses for } \\
3 \text { EC values } \\
\end{array}$ & $\begin{array}{l}0.02,0.09 \text { and } \\
0.35 \mathrm{~S} / \mathrm{m}\end{array}$ & $\begin{array}{l}\text { Thickness of plume was changed } \\
\text { from } 0.05 \text { to } 0.9 \text { at } 0.05 \mathrm{~m} \\
\text { increment }\end{array}$ \\
\hline
\end{tabular}

\section{Field testing using a lysimeter}

A lysimeter was constructed at the Meewathura experimental station of the Department of Agricultural Engineering, University of Peradeniya, Sri Lanka. The dimensions of the lysimeter were $4.0 \mathrm{~m} \times 1.0 \mathrm{~m} \times 1.5 \mathrm{~m}(\mathrm{~L} \mathrm{x} \mathrm{W} \mathrm{x} \mathrm{D)} \mathrm{and} \mathrm{thickness} \mathrm{of} \mathrm{the} \mathrm{side} \mathrm{walls} \mathrm{was} 0.1 \mathrm{~m}$ (Figure 2a).The lysimeter was filled with river sand (washed) and thickness of the unsaturated layer and saturated layer were maintained at the same depth similar to the conceptual model used in GprMax2D. As well as two iron bars were placed at $1.0 \mathrm{~m}$ (bar-A) and $3.0 \mathrm{~m}$ (bar-B) distance on top of the filled sand layer (Figure 2b). 


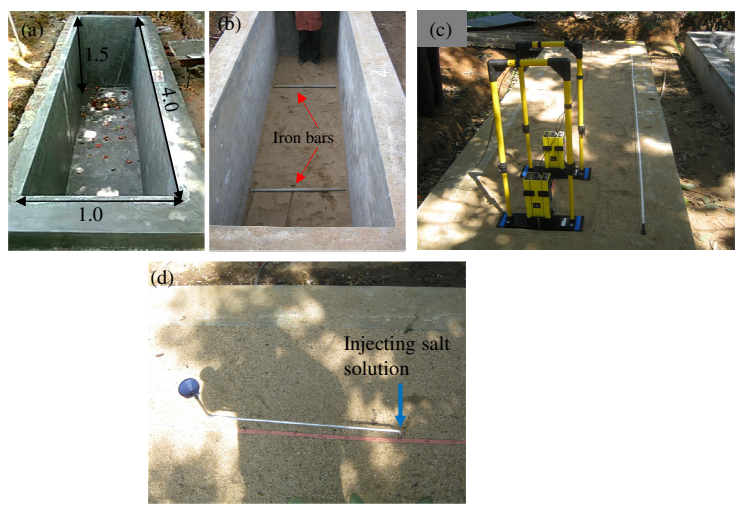

Fig. 2. Photographs of (a) completed lysimeter (b), lysimeter after placed iron bars as reflectors (c), GPR survey on the lysimeter (d) and salt water injection

After placing iron bars, the lysimeter was completely filled with sand (Figure 2c). Different concentrations of salt $(\mathrm{NaCl})$ solutions (different EC levels) were injected into the water table (Figure 2d) during the GPR surveys. The responses of GPR signals from reflectors were studied at each EC level. The Fixed Offset (FO) reflection survey mode was used when collecting GPR data using PuleEKKO-Pro GPR system with $200 \mathrm{MHz}$ antennas (Figure 2c). Table 2 shows the details for conducted GPR surveys on the lysimeter.

Table 2. Details of GPR survey on lysimeter and measured EC value of water sample.

\begin{tabular}{|c|c|c|c|}
\hline $\begin{array}{l}\text { Survey } \\
\text { number }\end{array}$ & Situation & $\begin{array}{l}\text { Water } \\
\text { sample } \\
\text { number }\end{array}$ & $\begin{array}{l}\text { EC } \\
(\mathbf{S} / \mathbf{m})\end{array}$ \\
\hline \multicolumn{4}{|c|}{ Before salt solution injection } \\
\hline Survey-1 & Dry sand & & \\
\hline Survey-2 & After wetting $(0.31 \mathrm{~L} / \mathrm{s}, 65$ minutes $)$ & & \\
\hline Survey-3 & After wetting $(0.17 \mathrm{~L} / \mathrm{s}$, for $15 \mathrm{~min})$ & 1 & $1.6 \times 10^{-4}$ \\
\hline \multicolumn{4}{|c|}{ After salt solution injection } \\
\hline Survey-4 & After adding $1 \mathrm{~L}$ salt solution $(\mathrm{C}=50 \mathrm{~g} / \mathrm{L})$ & 2 & $1.6 \times 10^{-2}$ \\
\hline Survey-5 & After addition $1 \mathrm{~L}$ salt solution $(\mathrm{C}=50 \mathrm{~g} / \mathrm{L})$ & 3 & $6.2 \times 10^{-2}$ \\
\hline Survey-6 & After adding $2 \mathrm{~L}$ salt solution $(\mathrm{C}=50 \mathrm{~g} / \mathrm{L})$ & 4 & \\
\hline Survey-7 & After adding $2 \mathrm{~L}$ salt solution $(\mathrm{C}=100 \mathrm{~g} / \mathrm{L})$ & 5 & $8.0 \times 10^{-2}$ \\
\hline Survey-8 & After adding $2 \mathrm{~L}$ of salt solution $(\mathrm{C}=200 \mathrm{~g} / \mathrm{L})$ & & \\
\hline Survey-9 & After adding $1 \mathrm{~L}$ of salt solution $(\mathrm{C}=400 \mathrm{~g} / \mathrm{L})$ & & \\
\hline Survey-10 & After adding $1 \mathrm{~L}$ of salt solution $(\mathrm{C}=500 \mathrm{~g} / \mathrm{L})$ & 6 & $\frac{15.9}{2} \times 10$ \\
\hline
\end{tabular}

\section{Analyzes of GPR survey response on lysimeter}

2D images of GPR data were developed using EKKO_View Deluxe and EKKO-View software (Sensors and Software Inc.). Raw GPR data were not processed with GPR processing techniques and therefore, it would help to recover the raw amplitude variation of each trace (Cassidy, 2007). Amplitudes of reflection events were picked using PickerV2 
software and then peak amplitude values were plotted with respect to the EC of each corresponding water sample.

\section{RESULTS AND DISCUSSION}

\section{Comparison of GPR wave amplitude for different models}

Figure $3 \mathrm{a}$ shows the 2D image for the model series I and Figure $3 \mathrm{~b}$ shows the variation of two-way travel time for three selected reflection events for traces A, B and C. According to these results, both A and B traces do not show any amplitude variation for all three reflected events as expected since all three layers have EC value of $0.0 \mathrm{~S} / \mathrm{m}$. Figure 4 shows the GPR response under three plume thicknesses for selected EC levels $(0.02 \mathrm{~S} / \mathrm{m}, 0.09 \mathrm{~S} / \mathrm{m}$ and 0.35 $\mathrm{S} / \mathrm{m}$ of simulated data) in the saturated sand layer with three reflection events for trace B. At $0.02 \mathrm{~S} / \mathrm{m}$ and $0.09 \mathrm{~S} / \mathrm{m}$ EC levels, reflections from the iron bar B and the bed rock are clear, but it is not clear at $0.35 \mathrm{~S} / \mathrm{m}$ EC level. In the area where $\mathrm{EC}=0.0 \mathrm{~S} / \mathrm{m}$, reflection from the bedrock and the bar-A has not changed in different model runs (the area from $0.0 \mathrm{~m}$ to $2.0 \mathrm{~m}$ on the $\mathrm{X}$ axis). Conversely, reflection from the bedrock and the bar-B in the area (from $2.0 \mathrm{~m}$ to $4.0 \mathrm{~m}$ on X-axis) where EC $>0.0 \mathrm{~S} / \mathrm{m}$, has gradually reduced with increasing EC levels. Statistical analysis revealed that the mean amplitude variation in thickness $1(0.2 \mathrm{~m})$ is not significantly different from thickness $2(0.4 \mathrm{~m})(\mathrm{p}=0.06648 ; \mathrm{n}=35)$, but significantly different from thickness $3(0.8 \mathrm{~m})(\mathrm{p}=0.00451 ; \mathrm{n}=35)$. Amplitude variation in thickness 2 is not significantly different from thickness $3(\mathrm{p}=0.29382 ; \mathrm{n}=35)$. Same as in model series II, wave amplitude values of the iron bars and the bedrock reflections gradually decreases with increasing plume thickness and increasing EC.
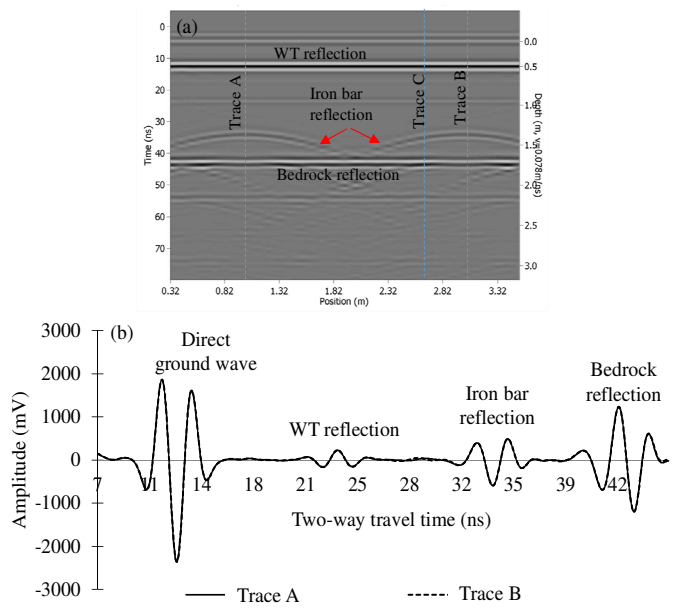

Fig. 3. GPR wave responses simulated using GprMax2D. (a) 2D image of the model series I. Traces A, B and C are shown in broken lines. (b) Amplitude variation of three reflected events of the trace $A$ and trace $B$. 


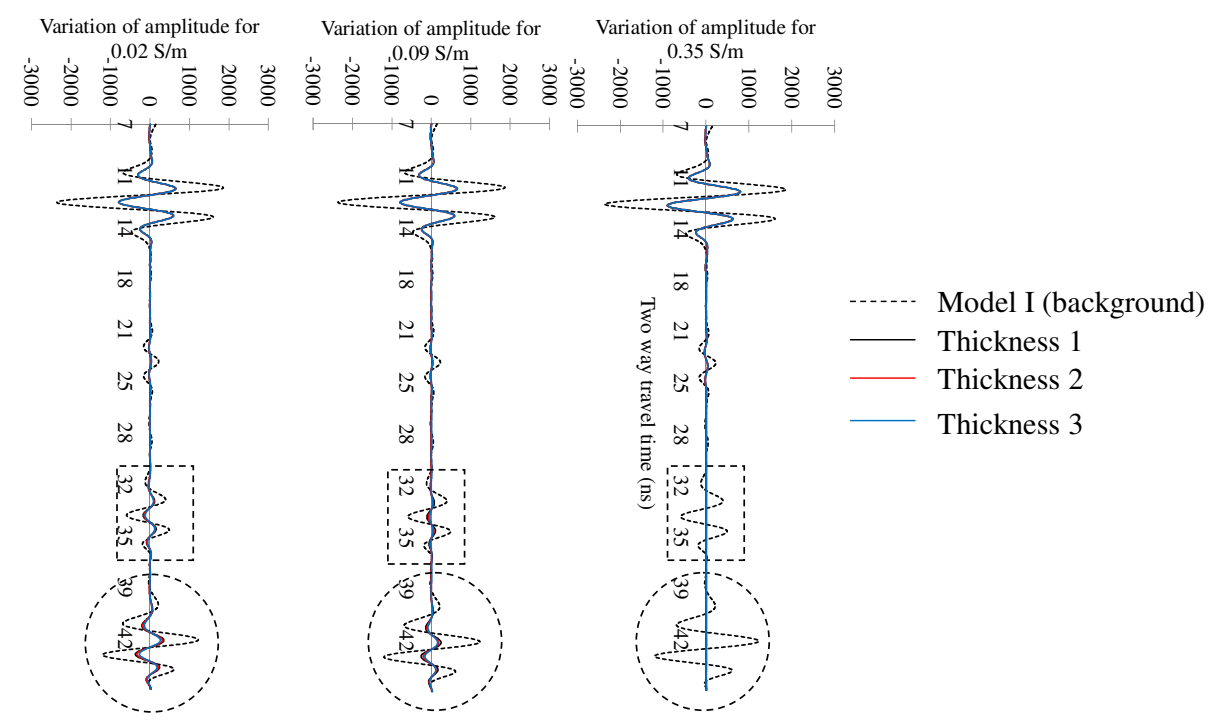

Fig.4. GPR reflected wave responses under different EC levels. Dashed box and dashed circle shows the reflections of iron bar and bed rock, respectively.

\section{GPR responses for lysimeter test}

The GPR survey-1 (Table 2) was conducted under dry condition (before wetting the media). Figure 6a shows the GPR 2D image for the lysimeter filled with dry sand. Reflections from bottom of the lysimeter and from the bar were interfered with each other due to high radar velocity.
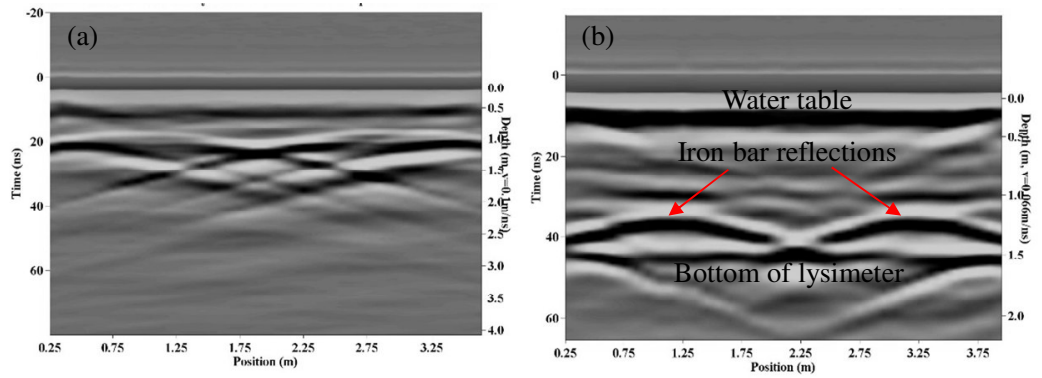

Fig. 6. GPR 2D image of lysimeter test (a) survey-1 (before water wetting), (b) survey2 (after water wetting)

After 65 minutes of wetting at $0.31 \mathrm{~L} / \mathrm{s}$ rate (totalling $1200 \mathrm{~L}$ of water), the survey- 2 was conducted and all three reflections are clear (Figure6 b) compared to the survey-1. This is one of the limitations of the GPR technique that it cannot produce high resolution images from a totally dried media. The main reason is that the spatial resolution increases by decreasing radar wave velocity with increasing moisture content (Davis and Annan, 1989; Huisman et al., 2003 and Galagedara et al., 2003). When salt solution was introduced to the water table (WT), reflection from the WT, iron bar (subsurface reflection) and bottom of the lysimeter should be disappeared due to energy attenuation (Cosgrave et al., 1987). The signal amplitude variations were also analyzed with respect to different EC values to find whether 
there is any significant reduction in amplitude values with increasing EC (contaminant in groundwater) in the saturated zone. Table 2 shows measured EC of water samples after each survey under different salt concentrations. Energy (amplitude) of reflected events gradually decreases and disappeared with time when increasing the concentration of the salt solution. Figure 7 shows the relationship between EC of the water sample and the amplitude values of iron bar reflection of trace B. Amplitude of iron bar "B" reflections were reduced linearly with increasing EC of the water (saturated zone). Theoretically, simulation study had a homogeneous media and GPR waves were changed only due to the effect of EC changes.

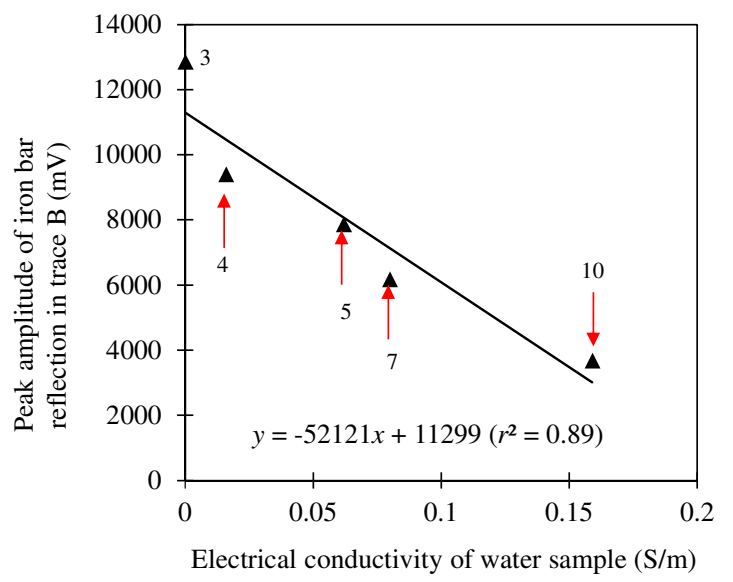

\section{Fig. 7. Variation of peak amplitude of iron bar reflection in trace $B$ with changing EC of water (arrow head shows the survey number).}

Both modelling results and lysimeter study show that the energy of GPR reflected wave reduces when the groundwater has high EC or highly contaminated with inorganic pollutant.

\section{CONCLUSIONS}

Results from both modelling and lysimeter studies revealed that the signal strength (wave amplitude) of the reflected wave decreases with increasing EC levels. Simulation study showed the disappearance of the subsurface reflection and wave amplitude reaching zero at higher EC levels (when EC >0.28 S/m). In addition, when the EC level was higher, the plume thickness does not have significant effect on the amplitude of the reflected wave. These results show that the GPR as a non-destructive method can be used to identify and map highly polluted areas with inorganic contaminants in groundwater. Further research is needed to verify the results under heterogeneous aquifer conditions.

\section{ACKNOWLEDGMENTS}

Crossing boundaries project for giving research fellowship, Dr. Giannopolous at University Edinburgh for giving free access to the GprMax2D and National Research Council of Sri Lanka for providing financial assistance to purchase a GPR system. 


\section{REFERENCES}

Annan, A.P. (1992). Ground Penetrating Radar Workshop Notes, Sensors and Software Inc. Mississauga, ON, Canada.

Calabrese, M., Zanzi, L. and Lualdi, M. (2004). Mapping an industrial landfill area from penetration of GPR data. Proceedings symposium on the Application of Geophysics to Engineering and Environmental Problems, Colorado Springs, Colorado, Paper ENG02: 14.

Cassidy, N.J. (2007). Evaluating LNAPL contamination using GPR signal attenuation analysis and dielectric property measurements practical implications for hydrological studies. Journal of Contaminant Hydrology, Vol. 94, 49 - 75.

Cosgrave, T.M., Greenhouse, J.P. and Barker, J.F. (1987). Shallow stratigraphic reflections from ground penetrating radar. In proceeding: First National outdoor action conference on aquifer restoration, Ground water monitoring, and geophysical methods.

Davis, J.L. and Annan, A.P. (1989). Ground penetrating padar for high resolution mapping of soil and rock stratigraphy. Geophysical Prospecting, Vol. 37, 531 - 551.

Galagedara, L.W., Parkin, G.W. and Redman, J.D. (2003). An analysis of the GPR direct ground wave method for soil water content measurement. Hydrological Processes, Vol. 17, $3615-3628$.

Hermozilha, H., Grangeia, C. and Matias, M.S. (2010). An integrated 3D constant offset GPR and resistivity survey on a sealed landfill - Ilhavo, NW Portugal. Journal of Applied Geophysics, Vol. 70, 58 - 71.

Huisman, J.A., Hubbard, S.S., Redman, J.D. and Annan, A.P. (2003). Measuring soil water content with ground penetrating radar: A review: Vadose Zone Journal, Vol. 2, 476 - 491.

Kelly, W.E. (1976). Geoelectric sounding for delineating groundwater contamination. Groundwater, Vol. 14(1), 1 - 10.

Lee, J.H. and Wang, W. (2009). Characterization of snow cover using ground penetrating radar for vehicle trafficability-experiment and modelling. Journal of Terramechanics, 46, 189 $-202$.

Robert, M.K. and David, E.D. (1997). Final covers for solid waste landfills and abandoned dumps. ASCE press and Thomas Telford, 1 Heron Quay, London, E14 4JD, UK.

Roy, J.W., Robillard, M.J., Watson, S.B. and Hayashi, M. (2009). Non-intrusive characterization methods for waste water-affected groundwater plumes discharging to an alpine lake. Environmental Monitoring and Assessment, Vol. 149, 201 - 211. 